\title{
Monitoring Radiation Doses during Diagnostic and Therapeutic Neurointerventional Procedures: Multicenter Study for Establishment of Reference Levels
}

\author{
Yon-Kwon Ihn, $\mathrm{MD}^{1}$, Bum-soo Kim, $\mathrm{MD}^{2}$, Hae Woong Jeong, $\mathrm{MD}^{3}$, Sang Hyun Suh, $\mathrm{MD}^{4}$, \\ Yoo Dong Won, $\mathrm{MD}^{5}$, Young-Jun Lee, $\mathrm{MD}^{6}$, Dong Joon Kim, $\mathrm{MD}^{7}$, Pyong Jeon, $\mathrm{MD}^{8}$, \\ Chang-Woo Ryu, MD ${ }^{9}$, Sang-il Suh, $\mathrm{MD}^{10}$, Dae Seob Choi, $\mathrm{MD}^{11}$, See Sung Choi, $\mathrm{MD}^{12}$, \\ Sang Heum Kim, $\mathrm{MD}^{13}$, Jun Soo Byun, $\mathrm{MD}^{14}$, Jieun Rho, $\mathrm{MD}^{15}$, Yunsun Song, $\mathrm{MD}^{16}$, \\ Woo Sang Jeong, $\mathrm{MD}^{17}$, Noah Hong, $\mathrm{MD}^{18}$, Sung Hyun Baik, $\mathrm{MD}^{19}$, Jeong Jin Park, $\mathrm{MD}^{20}$, \\ Soo Mee Lim, $\mathrm{MD}^{21}$, Jung-Jae Kim, $\mathrm{MD}^{22}$, Woong Yoon, $\mathrm{MD}^{23}$ \\ ${ }^{1}$ Department of Radiology, St. Vincent's Hospital, The Catholic University of Korea, Suwon, Korea \\ ${ }^{2}$ Department of Radiology, Seoul St. Mary's Hospital, The Catholic University of Korea, Seoul, Korea \\ ${ }^{3}$ Department of Radiology, Busan Paik Hospital, Inje University, Busan, Korea \\ ${ }^{4}$ Department of Radiology, Gangnam Severance Hospital, Yonsei University, Seoul, Korea \\ ${ }^{5}$ Department of Radiology, Uijeongbu St. Mary's Hospital, College of Medicine, The Catholic University of Korea, Uijeongbu, Korea \\ ${ }^{6}$ Department of Radiology, Hanyang University College of Medicine, Seoul, Korea \\ ${ }^{7}$ Department of Radiology, Severance Hospital, Yonsei Unviersity College of Medicine, Seoul, Korea \\ ${ }^{8}$ Department of Radiology, Samsung Medical Center, Sungkyunkwan University School of Medicine, Seoul, Korea \\ ${ }^{9}$ Department of Radiology, Kyung Hee University Hospital at Gangdong, Seoul, Korea \\ ${ }^{10}$ Department of Radiology, Korea University Guro Hospital, Korea University College of Medicine, Seoul, Korea \\ ${ }^{11}$ Department of Radiology, Gyeongsang National University Hospital, Gyeongsang National University School of Medicine, Jinju, Korea \\ ${ }^{12}$ Department of Radiology, Wonkwang University Hospital, Iksan, Korea \\ ${ }^{13}$ Department of Radiology, CHA Bundang Medical Center, CHA University, Seongnam, Korea \\ ${ }^{14}$ Department of Radiology, Chung-Ang University Hospital, Seoul, Korea \\ ${ }^{15}$ Department of Radiology, Pusan National University Yangsan Hospital, Yangsan, Korea \\ ${ }^{16}$ Department of Radiology, Asan Medical Center, University of Ulsan College of Medicine, Seoul, Korea \\ ${ }^{17}$ Department of Radiology, Ajou University Medical Center, Ajou University School of Medicine, Suwon, Korea \\ ${ }^{18}$ Department of Neurosurgery, Seoul National University Hospital, Seoul, Korea \\ ${ }^{19}$ Department of Radiology, Seoul National University Bundang Hospital, Seongnam, Korea \\ ${ }^{20}$ Department of Neurology, Konkuk University Medical Center, Seoul, Korea \\ ${ }^{21}$ Department of Radiology, Ewha Womans University Seoul Hospital, Seoul, Korea \\ ${ }^{22}$ Department of Neurosurgery, Ewha Womans University Seoul Hospital, Seoul, Korea \\ ${ }^{23}$ Department of Radiology, Chonnam National University Hospital, Gwangju, Korea
}

Purpose: To assess patient radiation doses during diagnostic and therapeutic neurointerventional procedures from multiple centers and propose dose reference level (RL).

Materials and Methods: Consecutive neurointerventional procedures, performed in 22 hospitals from December 2020 to June 2021, were retrospectively studied. We collected data from a sample of 429 diagnostic and 731 therapeutic procedures. Parameters including dose-area product (DAP), cumulative air kerma (CAK), fluoroscopic time (FT), and total number of image frames (NI) were obtained. RL were calculated as the 3rd quartiles of the distribution.

Results: Analysis of 1160 procedures from 22 hospitals confirmed the large variability in patient dose for similar procedures. RLs in terms of DAP, CAK, FT, and NI were $101.6 \mathrm{~Gy} \cdot \mathrm{cm}^{2}$, 711.3 mGy, 13.3 minutes, and 637 frames for cerebral angiography, $199.9 \mathrm{~Gy} \cdot \mathrm{cm}^{2}$, 3,458.7 mGy, 57.3 minutes, and 1,000 frames for aneurysm coiling, $225.1 \mathrm{~Gy} \cdot \mathrm{cm}^{2}$, 1,590 mGy, 44.7 minutes,
Copyright $\odot 2021$ Korean Society of Interventional Neuroradiology This is an Open Access article distributed under the terms of the Creative Commons Attribution Non-Commercial License (http://creativecommons.org/licenses/by-nc/4.0) which permits unrestricted non-commercial use, distribution, and reproduction in any medium, provided the original work is properly cited.

pISSN 2093-9043 eISSN 2233-6273 
and 800 frames for stroke thrombolysis, $412.3 \mathrm{~Gy} \cdot \mathrm{cm}^{2}$, 4,447.8 mGy, 99.3 minutes, and 1,621.3 frames for arteriovenous malformation (AVM) embolization, respectively. For all procedures, the results were comparable to most of those already published. Statistical analysis showed male and presence of procedural complications were significant factors in aneurysmal coiling. Male, number of passages, and procedural combined technique were significant factors in stroke thrombolysis. In AVM embolization, a significantly higher radiation dose was found in the definitive endovascular cure group.

Conclusion: Various RLs introduced in this study promote the optimization of patient doses in diagnostic and therapeutic interventional neuroradiology procedures. Proposed 3rd quartile DAP (Gy. $\left.\mathrm{cm}^{2}\right)$ values were 101.6 for diagnostic cerebral angiography, 199.9 for aneurysm coiling, 225.1 for stroke thrombolysis, and 412.3 for AVM embolization. Continual evolution of practices and technologies requires regular updates of RLS.

Key Words: Cerebral angiography; Diagnostic reference levels; Radiation monitoring; Intracranial aneurysm; Thrombectomy; Intracranial arteriovenous malformation

\author{
Correspondence to: \\ Yon-Kwon Ihn, MD \\ Department of Radiology, St. Vincent's \\ Hospital, The Catholic University of \\ Korea, 93 Jungbu-daero, Paldal-gu, \\ Suwon 16247, Korea \\ Tel: +82-31-249-7491 \\ Fax: +82-31-247-5713 \\ E-mail: ihn@catholic.ac.kr \\ Received: September 17, 2021 \\ Revised: October 13, 2021 \\ Accepted: October 18, 2021
}

\section{INTRODUCTION}

Cerebrovascular disease is one of the leading causes of death in Korea, and interventional neuroradiology (INR) procedures have increased substantially in both number and complexity. As the volume and types of procedures grow, we will start to see lengthy procedures to achieve better results. However, interventional radiological procedures can potentially expose a patient to high doses of radiation, which requires particular concern and continuous monitoring. ${ }^{1,2}$

Since interventional radiology involves prolonged use of $X$-rays, reference levels (RLs) for various procedures might be the next step in quality assurance and improvement. ${ }^{3}$ Similar to diagnostic reference levels (DRLs), continuously updated RLs in diagnostic and interventional radiology should provide a framework for physicians performing endovascular treatment in order to control, limit, and reduce radiation exposure for patients and personnel. ${ }^{3-5}$

Previous studies in Korea and other countries have investigated RLs and reported large variation within hospitals using different RL guidelines. ${ }^{5-10}$ Recognizing the need for continuous dose monitoring in diagnostic cerebral angiography and the fact that no such multi-center study has ever been carried out regarding other INR procedures, the authors collected data concerning the dose to patients undergoing some of the most common INR procedures performed in Korea.

The purposes of the present study were (1) to obtain baseline radiation dose data by evaluation of patient exposure at multiple centers, (2) to compare these data with the recent literature from other studies, and (3) to propose new DRLs.

\section{MATERIALS AND METHODS}

\section{Study Design and Patient Selection}

This was a multicenter retrospective study with the participation of 22 hospitals involving prospectively and consecutively collected data between December 2020 and June 2021. The target hospitals were secondary or tertiary hospitals designated as local medical centers in South Korea and endovascular treatment-capable institutions. As radiation doses show a wide distribution with respect to pathology and type of neurointerventional procedure, we focused on 4 standardized cerebral angiographic examinations. Each center was asked to register 20 cases of diagnostic cerebral angiography, 15 cases of aneurysm embolization, 15 cases of stroke thrombolysis/thrombectomy, and 5 cases of arteriovenous malformation (AVM) embolization, respectively. In diagnostic angiography, the age of participants ranged from 17 to 86 years with mean age of 56 years. For each examination, the centers were asked to fill out a questionnaire containing various information regarding radiation data. The $X$-ray systems used in this study were all biplane digital subtraction angiography (DSA) (14 Siemens, 7 Philips, and 1 GE machines). Institutional ethics board approval was granted for this retrospective descriptive cohort study performed at 
various institutions. A waiver of the need for consent was obtained for this Health Insurance Portability and Accountability Act compliant survey research.

\section{Procedures Included}

The neurointerventional procedures were divided into 2 groups: (1) diagnostic cerebral angiography for aneurysm evaluation and (2) therapeutic procedures, namely aneurysmal coil embolization, mechanical thrombolysis/thrombectomy for ischemic stroke, and AVM embolization. For a diagnostic angiography procedure, we focused on aneurysmal evaluation, and follow-up after clipping or coiling of an aneurysm was excluded. The procedures were performed by an experienced interventional neuroradiologist or clinical fellow undergoing interventional neuroradiology training, all using their own protocols.

\section{Data Collection}

Collected patient radiation dose indicators were as follows: dose-area product (DAP), cumulative air kerma (CAK), fluoroscopic exposure time, and number of angiographic image acquisitions. Collected data were entered onto a Microsoft Office Excel 2010 (Microsoft, Redmond, WA, USA) spreadsheet. Patient sex, patient age, procedure type, and number of exposures were recorded for all procedures. For the aneurysm coiling procedure, the following additional parameters were recorded: location, size of aneurysm, embolization technique, and presence of peri-procedural complication. For stroke thrombolysis, the following additional parameters were recorded: level of occlusion, thrombectomy technique (stent retriever, direct aspiration, or combined), trial number of device passage, and final angiographic results. For AVM embolization, the following additional parameters were recorded: size and location of AVM nidus, Spetzler-Martin grade, and purpose of embolization. Data were analyzed to assess mean \pm standard deviation for each parameter. As collected radiation doses will show a skewed distribution with extreme values and a long upper tail, 75th percentile values were also analyzed to propose DRL.

\section{Statistics/Data Analysis}

A descriptive analysis of the data was performed. Statistical analysis was performed with Statistical Package for Social Scientists (SPSS) software version 23 (IBM, Armonk, NY, USA). Median, mean, and maximum and minimum radiation doses were calculated for each of the 4 procedures. Except for diagnostic angiography, other procedure-related variables were analyzed using 2 different statistical tests depending

Table 1. Summary of DAP, cumulative air kerma, fluoroscopy time, image frames for interventional procedures

\begin{tabular}{|c|c|c|c|c|c|}
\hline & & $\operatorname{DAP}\left(\mathrm{Gy} \cdot \mathrm{cm}^{2}\right)$ & $\begin{array}{l}\text { Cumulative air kerma } \\
\text { (mGy) }\end{array}$ & Fluoroscopy time (min) & $\begin{array}{c}\text { Number of image } \\
\text { frames }\end{array}$ \\
\hline $\begin{array}{l}\text { Diagnostic } \\
\text { cerebral } \\
\text { angiography } \\
(n=429)\end{array}$ & $\begin{array}{l}\text { Mean } \pm \text { SD } \\
\text { Median } \\
\text { 3rd quartile } \\
\text { Range } \\
\text { 25th percentile }\end{array}$ & $\begin{array}{c}78.0 \pm 43 \\
70.4 \\
101.6 \\
12.5-357 \\
45.8\end{array}$ & $\begin{array}{c}541.5 \pm 333.2 \\
449.2 \\
711.3 \\
105.3-2,836 \\
294.3\end{array}$ & $\begin{array}{c}10.4 \pm 6.4 \\
8.6 \\
13.3 \\
2.5-50 \\
6.0\end{array}$ & $\begin{array}{c}511.1 \pm 208.5 \\
464.0 \\
637 \\
52-1,449 \\
371\end{array}$ \\
\hline $\begin{array}{l}\text { Aneurysm coiling } \\
(n=327)\end{array}$ & $\begin{array}{l}\text { Mean } \pm S D \\
\text { Median } \\
\text { 3rd quartile } \\
\text { Range } \\
\text { 25th percentile }\end{array}$ & $\begin{array}{c}151.0 \pm 96.8 \\
130.6 \\
199.9 \\
12.3-728.9 \\
84.9\end{array}$ & $\begin{array}{c}2,622.8 \pm 2,110.7 \\
2,104.0 \\
3,458.7 \\
342.7-21,280.0 \\
1,255.0\end{array}$ & $\begin{array}{c}45.8 \pm 30.7 \\
40.9 \\
57.3 \\
2.8-318.4 \\
24.7\end{array}$ & $\begin{array}{c}803.7 \pm 540.0 \\
680.0 \\
1,000 \\
44-3,175 \\
424\end{array}$ \\
\hline $\begin{array}{l}\text { Stroke } \\
\text { thrombolysis } \\
(n=326)\end{array}$ & $\begin{array}{l}\text { Mean } \pm \text { SD } \\
\text { Median } \\
\text { 3rd quartile } \\
\text { Range } \\
\text { 25th percentile }\end{array}$ & $\begin{array}{c}176.2 \pm 118.7 \\
150.4 \\
225.1 \\
9.9-787.2 \\
92.5\end{array}$ & $\begin{array}{c}1,263.5 \pm 918.2 \\
1,036.0 \\
1,590.0 \\
61.3-6,804 \\
587.1\end{array}$ & $\begin{array}{c}35.1 \pm 26.4 \\
28.6 \\
44.7 \\
3.8-163.9 \\
15.2\end{array}$ & $\begin{array}{c}630.2 \pm 619.0 \\
434.0 \\
800.0 \\
58-4,870 \\
219.8\end{array}$ \\
\hline $\begin{array}{l}\text { AVM embolization } \\
(n=78)\end{array}$ & $\begin{array}{l}\text { Mean } \pm S D \\
\text { Median } \\
\text { 3rd quartile } \\
\text { Range } \\
\text { 25th percentile }\end{array}$ & $\begin{array}{c}300.1 \pm 184.2 \\
264.3 \\
412.3 \\
15.1-835.0 \\
167.6\end{array}$ & $\begin{array}{c}3,673.8 \pm 2,923.0 \\
3,073.5 \\
4,447.8 \\
84.7-13,245 \\
1,772.8\end{array}$ & $\begin{array}{c}77.2 \pm 50.1 \\
63.1 \\
99.3 \\
2.2-245.0 \\
41.3\end{array}$ & $\begin{array}{c}1,293.8 \pm 1,061.6 \\
1,016.5 \\
1,621.3 \\
126.0-5,554 \\
588.0\end{array}$ \\
\hline
\end{tabular}

DAP, dose-area product; AVM, arteriovenous malformation; SD, standard deviation. 
on the number of groups per variable. Variables were compared according to the t-test if data were normally distributed between 2 groups. Between 3 groups, when statistically significant differences occurred, the ANOVA test with Tukey's hostly significant difference (HSD) post hoc test for multiple comparisons was performed. A P-value of less than 0.05 was considered statistically significant.

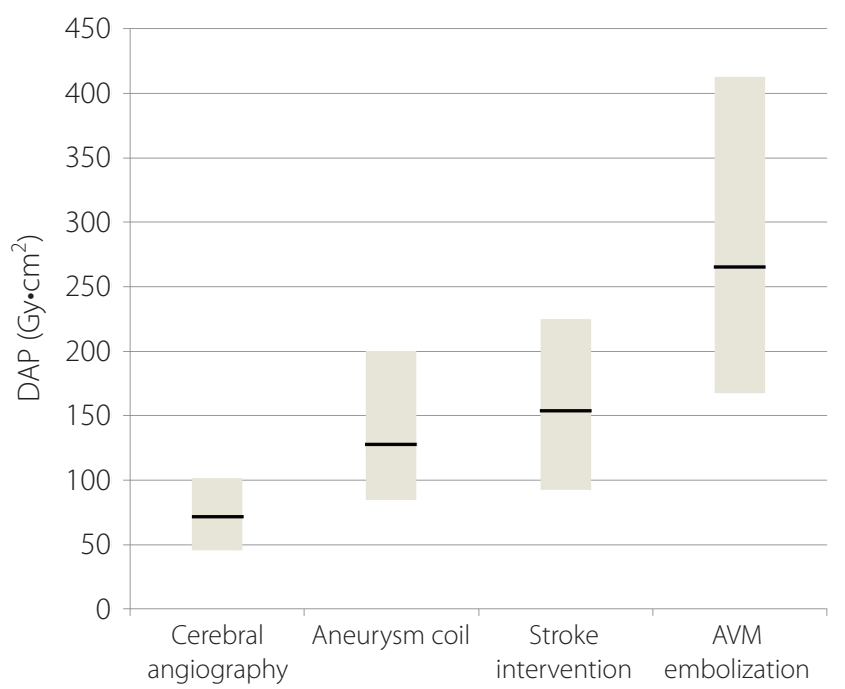

Fig. 1. Box plot of DAP for the neurovascular procedures analysed. The lower boundary of the box is the 25th percentile value, the upper boundary of the box is the 75th percentile value, the horizontal line within the box is the median value. DAP, dose-area product; AVM, arteriovenous malformation.

\section{RESULTS}

A total of 1,160 patients who underwent neurointerventional procedures were eligible for inclusion. Of the 1,160 procedures, 429 diagnostic cerebral angiograms, 327 aneurysm coilings, 326 stroke thrombolysis, and 78 AVM embolization procedures were performed. Median DAPs were as follows: diagnostic cerebral angiography, $70.4 \mathrm{~Gy} \cdot \mathrm{cm}^{2}$; aneurysm coiling, $130.6 \mathrm{~Gy} \cdot \mathrm{cm}^{2}$; stroke thrombolysis $150.4 \mathrm{~Gy} \cdot \mathrm{cm}^{2}$; and AVM embolization, $264.3 \mathrm{~Gy} \cdot \mathrm{cm}^{2}$. Detailed DAP distributions are illustrated in Table 1 and Fig. 1 demonstrates the range of radiation doses for each procedure type.

In diagnostic cerebral angiography, the mean DAP \pm standard deviation was $78.0 \pm 43 \mathrm{~Gy} \cdot \mathrm{cm}^{2}$ for DAP, $541.5 \pm 333.2 \mathrm{mGy}$ for CAK, 10.4 \pm 6.4 minutes for fluoroscopic time (FT), and 511.1 \pm 208.5 frames for angiographic image frames. The third quartiles, which may be set as a DRL, were $101.6 \mathrm{~Gy} \cdot \mathrm{cm}^{2}$ for DAP, and 711.3 mGy for cumulative air kerma, 13.3 minutes for fluoroscopy times, and 637 for number of image frames.

\section{Radiation Dose for Aneurysm Coiling}

Patient characteristics are summarized in Table 2. We identified a total of 327 patients (30.2\%; 99 males, and 69.8\%, 228 females, mean age 60.9 years) with either an unruptured or ruptured intracranial aneurysm. The median aneurysm size was $5.4 \mathrm{~mm}$, with a minimum diameter of $2.3 \mathrm{~mm}$ and a maximum diameter of $18.1 \mathrm{~mm}$. In total, 279 (85.3\%) out of a total of 327 aneurysms were located at the anterior circulation and 48 (14.7\%) aneurysms at the posterior circulation. Regarding the endovascular treatment technique, 159/327

\section{Table 2. Characteristics of 327 patients with a cerebral aneurysm undergoing endovascular treatment}

\begin{tabular}{|c|c|c|}
\hline Variable & \multicolumn{2}{|c|}{ Value } \\
\hline Age, mean (range) & \multicolumn{2}{|c|}{60.9 y $(17-92 y)$} \\
\hline \multicolumn{3}{|l|}{ Sex } \\
\hline Male $(n=99)$ & \multicolumn{2}{|c|}{$30.20 \%$} \\
\hline Female $(n=228)$ & \multicolumn{2}{|c|}{$69.80 \%$} \\
\hline Aneurysm size, median (range) & \multicolumn{2}{|c|}{$5.4 \mathrm{~mm}(2.3-18.1 \mathrm{~mm})$} \\
\hline \multicolumn{3}{|l|}{ Procedural complication } \\
\hline Without & \multicolumn{2}{|c|}{313} \\
\hline \multirow[t]{2}{*}{ With } & \multicolumn{2}{|c|}{14} \\
\hline & Anterior circulation $(n=279)$ & Posterior circulation $(n=48)$ \\
\hline Coiling (simple or double microcatheter) $(n=159)$ & 145 & 14 \\
\hline Balloon or stent assisted $(n=57)$ & 127 & 30 \\
\hline Flow diverter $(n=11)$ & 7 & 4 \\
\hline
\end{tabular}


Table 3. DAP, AK, fluroscopy time regarding aneurysm treatment

\begin{tabular}{|c|c|c|c|}
\hline Variable & Mean DAP $\left(\mathrm{Gy} \cdot \mathrm{cm}^{2}\right)$ & AK (mGy) & $\mathrm{FT}$ (min) \\
\hline \multicolumn{4}{|l|}{ Sex } \\
\hline Male $(n=99)$ & $168.9 \pm 117$ & $2,935 \pm 2,401$ & $46.3 \pm 31.3$ \\
\hline Female $(n=228)$ & $137.8 \pm 91$ & $2,464 \pm 2,142$ & $45.5 \pm 32.7$ \\
\hline P-value & $0.019^{*}$ & 0.112 & 0.857 \\
\hline \multicolumn{4}{|l|}{ Aneurysm location } \\
\hline Anterior $(n=279)$ & $148.9 \pm 94.1$ & $2,568 \pm 2,034$ & $45.6 \pm 31.5$ \\
\hline Posterior $(n=48)$ & $163.6 \pm 111.4$ & $2,938 \pm 2,507$ & $47.0 \pm 25.6$ \\
\hline P-value & 0.329 & 0.263 & 0.768 \\
\hline \multicolumn{4}{|l|}{ Procedural complication } \\
\hline Without (n=313) & $144 \pm 86$ & $2,487 \pm 1,811$ & $43.3 \pm 25.0$ \\
\hline With $(n=14)$ & $309 \pm 168$ & $5,655 \pm 4,758$ & $102.9 \pm 70.4$ \\
\hline P-value & $0.03^{*}$ & $0.027^{*}$ & $0.007^{*}$ \\
\hline \multicolumn{4}{|l|}{ Endovascular technique } \\
\hline Simple $(S)(n=159)$ & $143.3 \pm 94.8$ & $2,323 \pm 1,721$ & $42.1 \pm 27.4$ \\
\hline Assisted (A) $(n=157)$ & $160.7 \pm 99.7$ & $2,994 \pm 2,448$ & $50.6 \pm 33.9$ \\
\hline FlowDiverter (F) $(n=11)$ & $125.5 \pm 72.1$ & $1,652 \pm 522$ & $30.8 \pm 11.3$ \\
\hline \multirow[t]{3}{*}{ P-value } & S vs. A: $P=0.243$ & S vs. A: $P=0.012^{*}$ & S vs. A: $P=0.035^{*}$ \\
\hline & S vs. F: $P=0.826$ & S vs. F: $P=0.056$ & S vs. F: $P=0.459$ \\
\hline & A vs. $F: P=0.472$ & A vs. F: $P=0.099$ & A vs. F: $P=0.093$ \\
\hline
\end{tabular}

Mean value were calculated using t-test and are shown ad mean \pm standard deviaton.

DAP, dose-area product; AK, air-kerma; FT, fluoroscopic time.

*Remained significant.

Table 4. Characteristics of 326 patients with ischemic stroke undergoing mechanical thrombolysis

\begin{tabular}{|c|c|c|}
\hline Variable & \multicolumn{2}{|c|}{ Value } \\
\hline Age, mean (range) & \multicolumn{2}{|c|}{70.84 y $(29-93$ y) } \\
\hline \multicolumn{3}{|l|}{ Sex } \\
\hline Male $(n=186)$ & \multicolumn{2}{|c|}{$57.10 \%$} \\
\hline Female $(n=140)$ & \multicolumn{2}{|c|}{$42.90 \%$} \\
\hline \multirow[t]{2}{*}{ NIHSS, median (range) } & \multicolumn{2}{|c|}{$13(2-40)$} \\
\hline & Anterior circulation ( $n=283$ ) & Posterior circulation $(n=43)$ \\
\hline Aspiration $(n=80)$ & 63 & 17 \\
\hline Stentriever $(n=113)$ & 105 & 8 \\
\hline Combined $(n=134)$ & 115 & 18 \\
\hline Success of recanalization ( $\mathrm{TICl}$ ) & $<2 a(n=48)$ & $\geq 2 b(n=278)$ \\
\hline \multicolumn{3}{|l|}{ Number of passage } \\
\hline 1 & \multicolumn{2}{|c|}{$n=139$} \\
\hline 2 & \multicolumn{2}{|c|}{$\mathrm{n}=77$} \\
\hline$\geq 3$ & \multicolumn{2}{|c|}{$\mathrm{n}=110$} \\
\hline
\end{tabular}

NIHSS, National Institute of Health Stroke Scale; TICl, thrombolysis in cerebral infarction scale. 
(48.6\%) patients were treated with a simple or double microcatheter technique, 157/327 (48.0\%) by a balloon or stent-assisted technique, and 11/327 (3.4\%) by using a flow diverter. Of the 327 patients, we had 14 (4.3\%) cases of peri-procedural complications. Results of radiation doses and fluoroscopy time are illustrated in Tables 1 and 3. In aneurysmal embolization, the mean DAP \pm standard deviation was $151.0 \pm 96.8$ Gy. $\mathrm{cm}^{2}$ for DAP, 2,622.8 $\pm 2,110.7 \mathrm{mGy}$ for CAK, $45.8 \pm 30.7 \mathrm{~min}$ utes for $F T$, and $803.7 \pm 540.0$ frames for angiographic image frames. The third quartiles, which may be set as a DRL, were 199.9 Gy.cm² for DAP, and 3458.7 mGy for cumulative air kerma, 57.3 minutes for fluoroscopy times, and 1,000 for number of image frames.
Pairwise comparison of mean DAP between different sex groups reached statistical significance $(P<0.05$; Table 3$)$. Concerning aneurysm location, mean DAP, air-kerma (AK), and FT values did not show statistical significant difference ( $P>0.05$; Table 3). Concerning the presence or absence of peri-procedural complications, pairwise comparisons of mean DAP, AK, and FT groups were significantly different $(P<0.05$; Table 3). The mean DAP of the simple (or double) microcatheter technique was $143.3 \pm 94.88 \mathrm{~Gy} \cdot \mathrm{cm}^{2}$, $160.7 \pm 99.7 \mathrm{~Gy} \cdot \mathrm{cm}^{2}$ for assisted (balloon or stent) technique, and 125.5 $\pm 72.1 \mathrm{mGy}$ for flow diverter. Pairwise comparisons of mean DAP between the 3 groups did not reach statistical significance.

Table 5. DAP, AK, fluroscopy time regarding mechanical thrombolysis

\begin{tabular}{|c|c|c|c|}
\hline Variable & Mean DAP $\left(\mathrm{Gy} \cdot \mathrm{cm}^{2}\right)$ & AK (mGy) & $\mathrm{FT}(\mathrm{min})$ \\
\hline \multicolumn{4}{|l|}{ Sex } \\
\hline Male $(n=186)$ & $190 \pm 124$ & $1,342 \pm 948$ & $33.2 \pm 25$ \\
\hline Female $(n=140)$ & $151 \pm 116$ & $1,118 \pm 892$ & $36.9 \pm 29.4$ \\
\hline P-value & $0.006^{*}$ & $0.04^{*}$ & 0.245 \\
\hline \multicolumn{4}{|l|}{ Occlusion site } \\
\hline Anterior $(n=283)$ & $174 \pm 114$ & $1,244 \pm 883$ & $34.9 \pm 26.7$ \\
\hline Posterior $(n=43)$ & $192 \pm 146$ & $1,385 \pm 1,125$ & $36.0 \pm 24.3$ \\
\hline P-value & 0.345 & 0.343 & 0.799 \\
\hline \multicolumn{4}{|c|}{ Result of recanalization } \\
\hline$<\mathrm{TICl} 2 \mathrm{a}(\mathrm{n}=48)$ & $177 \pm 120$ & $1,246 \pm 904$ & $34.3 \pm 26.3$ \\
\hline$\geq \mathrm{TICl} 2 \mathrm{~b}(\mathrm{n}=278)$ & $170 \pm 109$ & $1,358 \pm 998$ & $39.8 \pm 26.2$ \\
\hline P-value & 0.725 & 0.433 & 0.178 \\
\hline \multicolumn{4}{|c|}{ Number of device passage } \\
\hline 1 & $128 \pm 77$ & $875 \pm 560$ & $24 \pm 17$ \\
\hline 2 & $179 \pm 114$ & $1,197 \pm 766$ & $35 \pm 25$ \\
\hline$\geq 3$ & $236 \pm 137$ & $1,806 \pm 1,103$ & $49 \pm 30$ \\
\hline \multirow[t]{3}{*}{ P-value } & 1 vs. $2: P=0.004^{*}$ & 1 vs. $2: P=0.018^{*}$ & 1 vs. $2: P=0.005^{*}$ \\
\hline & $1 \mathrm{vs} . \geq 3: P=0.000^{*}$ & 1 vs. $\geq 3: P=0.000^{*}$ & 1 vs. $\geq 3: P=0.000^{*}$ \\
\hline & 2 vs. $\geq 3: P=0.001^{*}$ & $2 v s . \geq 3: P=0.000^{*}$ & 2 vs. $\geq 3: P=0.000^{*}$ \\
\hline \multicolumn{4}{|l|}{ Technique } \\
\hline Aspiration (A) & $132 \pm 118$ & $866 \pm 641$ & $24.3 \pm 22.5$ \\
\hline Stentriever (S) & $168 \pm 102$ & $1,188 \pm 759$ & $30.2 \pm 21.6$ \\
\hline Combined (C) & $208 \pm 123$ & $1,558 \pm 1,067$ & $45.4 \pm 28.4$ \\
\hline \multirow[t]{3}{*}{ P-value } & A vs. S: $P=0.09$ & A vs. S: $P=0.034^{*}$ & A vs. S: $P=0.243$ \\
\hline & A vs. $C: P=0.00^{*}$ & A vs. $C: P=0.003^{*}$ & S vs. $C: P=0.000^{*}$ \\
\hline & S vs. C: $P=0.019^{*}$ & S vs. $C: P=0.00^{*}$ & A vs. $C: P=0.000^{*}$ \\
\hline
\end{tabular}

DAP, dose-area product; AK, air-kerma; FT, fluoroscopic time; TICl, thrombolysis in cerebral infarction scale.

*Remained significant. 


\section{Radiation Dose for Stroke Thrombolysis}

Patient characteristics are summarized in Table 4. A total of 326 patients received mechanical thrombectomy, with 140 (42.9\%) males and 186 (57.1\%) females. The mean age was 70.8 years old. The median NIHSS was 13, range between 2 and 40 . Out of the 326 thrombectomized patients, 283 (86.8\%) cases developed in the anterior circulation and 43 (13.2\%) in the posterior circulation. Regarding the thrombolysis technique, 80/326 (24.5\%) patients were treated by an aspiration technique, 113/326 (34.7\%) by a stentriver, and 133/326 (40.8\%) by a combination technique. Of the 326 patients, we had 278 (85.3\%) cases of successful recanalization (greater than thrombolysis in cerebral infarction scale grade $2 b)$. The trial number of device passage for thrombectomy were as follows: once (139 cases, 42\%), twice (77 cases, 24\%), and more than 3 times (110 cases, 34\%), respectively.

Results of radiation doses and fluoroscopy times are illustrated in Tables 1 and 5. In stroke thrombolysis, the mean $\mathrm{DAP} \pm$ standard deviation was $176.2 \pm 118.7 \mathrm{~Gy} \cdot \mathrm{cm}^{2}$ for DAP, 1,263.5 $\pm 918.2 \mathrm{mGy}$ for CAK, 35.1 \pm 26.4 minutes for $F T$, and $630.2 \pm 619.0$ frames for angiographic image frames. The third quartiles, which may be set as a DRL, were $225.1 \mathrm{~Gy} \cdot \mathrm{cm}^{2}$ for DAP, 1,590 mGy for cumulative air kerma, 44.7 minutes for fluoroscopy times, and 800 for number of image frames.

Pairwise comparison of mean DAP, AK between different sex groups reached statistical significance $(P<0.05$; Table 5).
Concerning the occlusion site and result of successful recanalization, mean DAP, AK, and FT values did not show statistical significant difference ( $P>0.05$; Table 5). Concerning the trial number of device passage, pairwise comparison of mean DAP, AK, and FT between groups were significantly different for all variables ( $P<0.05$; Table 5). Pairwise comparision of different thrombolysis technique groups reached statistical significance in terms of mean DAP, AK, and FT, especially between aspiration and combined technique or between stentriever and combined technique groups.

\section{Radiation Dose for AVM Embolization}

Patient characteristics are summarized in Table 6. A total of 78 AVM cases were treated, 42 (53\%) were male and 36 (47\%) were female. The mean age was 40.6 years old. The median size of AVM nidus was $2.5 \mathrm{~cm}$, ranging from $0.8 \mathrm{~cm}$ to $6.1 \mathrm{~cm}$. Out of the 78 patients, 59 (75.6\%) AVM procedures were performed at the anterior circulation and 19 (24.4\%) at the posterior circulation. Regarding the purpose of embolization of AVM, 22 (28.2\%) patients were treated before operative resection, 21 (26.9\%) patients before or after radiosurgery, and 35 (44.9\%) patients for complete cure. Spetzler-Martin grades of pre-embolization were I in 18 cases (23\%), II in 36 (46\%), III in 18 (23\%), IV in 5 (6\%), and V in 1 (1\%), respectively.

Results of radiation doses and fluoroscopy time are illustrated in Tables 1 and 7. In AVM embolization, the mean

\section{Table 6. Characteristics of 78 patients with AVM undergoing embolization}

\begin{tabular}{|c|c|c|}
\hline Variable & \multicolumn{2}{|c|}{ Value } \\
\hline Age, mean (range) & \multicolumn{2}{|c|}{40.6 y $(6-80 y)$} \\
\hline \multicolumn{3}{|l|}{ Sex } \\
\hline Male $(n=42)$ & \multicolumn{2}{|c|}{$53 \%$} \\
\hline Female $(n=36)$ & \multicolumn{2}{|c|}{$47 \%$} \\
\hline Size of AVM Nidus, median (range) & \multicolumn{2}{|c|}{$2.5 \mathrm{~cm}(0.8-6.1 \mathrm{~cm})$} \\
\hline \multicolumn{3}{|l|}{ Spetzler-Martin grade } \\
\hline 1 & \multicolumn{2}{|c|}{$n=18$} \\
\hline 2 & \multicolumn{2}{|c|}{$n=36$} \\
\hline 3 & \multicolumn{2}{|c|}{$n=18$} \\
\hline 4 & \multicolumn{2}{|c|}{$n=5$} \\
\hline \multirow[t]{2}{*}{5} & \multicolumn{2}{|c|}{$n=1$} \\
\hline & Anterior circulation $(n=59)$ & Posterior circulation $(n=19)$ \\
\hline Preoperative & 19 & 3 \\
\hline Pre radiosurgery & 16 & 5 \\
\hline Curative & 24 & 11 \\
\hline
\end{tabular}

AVM, arteriovenous malformation. 
DAP \pm standard deviation was $300.1 \pm 184.2 \mathrm{~Gy} \cdot \mathrm{cm}^{2}$ for DAP, 3,673.8 $\pm 2,923.0$ mGy for CAK, 77.2 \pm 50.1 minutes for $F T$, and 1,293.8 $\pm 1,061.6$ frames for angiographic image frames. The third quartiles, which may be set as a DRL, were $412.3 \mathrm{~Gy} \cdot \mathrm{cm}^{2}$ for DAP, 4,447.8 mGy for cumulative air kerma, 99.3 minutes for fluoroscopy times, and 1,621.3 for number of image frames.

Pairwise comparison of mean DAP and AK between different sex groups did not reach statistical significance $(P>0.05)$. Concerning the AVM location, mean DAP, AK, and FT values did not show statistical significant difference $(P>0.05)$. Concerning the size of the nidus, pairwise comparison of mean DAP, AK, and FT between groups did not reach statistical significance $(P>0.05)$. Concerning the purpose of embolization, pairwise comparison between groups revealed statistical significance in terms of mean DAP, AK, and FT. Radiation dose tended to increase in the curative embolization group.

\section{DISCUSSION}

Neurointerventional procedures are increasingly used. Due to the complexities of the cerebrovascular anatomy and the procedures themselves, these procedures often require a long time to perform. With more and more complex procedures, radiation dose for patients is an important issue. As a tool for optimization and quality improvement of practices, the need for establishing and monitoring radiation doses for neurointerventional procedures is obvious.

According to the ICRP 135 publication, ${ }^{4}$ application of several radiation dose metrics (e.g., DAP and FT) is recommended for DRL establishment of fluoroscopically guided interventions. In this context, the DRL value is defined as the 75th percentile of the distribution of the DRL quantity, representing a commonly calculated radiation dose metric in neurointerventional procedures.

Table 7. DAP, AK, and fluoroscopy time regarding AVM embolization

\begin{tabular}{|c|c|c|c|}
\hline Variable & Mean DAP $\left(\mathrm{Gy} \cdot \mathrm{cm}^{2}\right)$ & AK (mGy) & $\mathrm{FT}$ (min) \\
\hline \multicolumn{4}{|l|}{ Sex } \\
\hline Male $(n=42)$ & $325 \pm 199$ & $4,182 \pm 3,356$ & $79 \pm 51$ \\
\hline Female $(n=36)$ & $270 \pm 162$ & $3,080 \pm 2,220$ & $75 \pm 49$ \\
\hline P-value & 0.195 & 0.097 & 0.757 \\
\hline \multicolumn{4}{|l|}{ Location of AVM } \\
\hline Anterior $(n=59)$ & $288 \pm 175$ & $3,636 \pm 3,065$ & $76 \pm 48$ \\
\hline Posterior $(n=19)$ & $337 \pm 208$ & $3,853 \pm 2,623$ & $78 \pm 56$ \\
\hline P-value & 0.302 & 0.775 & 0.927 \\
\hline \multicolumn{4}{|l|}{ Size of Nidus (cm) } \\
\hline$<3 \mathrm{~cm}(\mathrm{~A})$ & $286 \pm 175$ & $3,390 \pm 2,658$ & $66 \pm 42$ \\
\hline $3-6 \mathrm{~cm}(\mathrm{~B})$ & $339 \pm 207$ & $4,667 \pm 3,671$ & $100 \pm 59$ \\
\hline$>6 \mathrm{~cm}(\mathrm{C})$ & $325 \pm 233$ & $3,086 \pm 2,205$ & $105 \pm 62$ \\
\hline \multirow[t]{3}{*}{ P-value } & A vs. $B: P=0.538$ & A vs. $B: P=0.242$ & A vs. $B: P=0.038^{*}$ \\
\hline & B vs. C: $P=0.992$ & B vs. C: $P=0.660$ & B vs. C: $P=0.984$ \\
\hline & A vs. C: $P=0.932$ & A vs. C: $P=0.983$ & A vs. C: $P=0.376$ \\
\hline \multicolumn{4}{|l|}{ Purpose of embolization } \\
\hline Preoperative $(0)(n=21)$ & $296 \pm 167$ & $2,975 \pm 1,842$ & $85 \pm 52$ \\
\hline Pre radiosurgery $(R)(n=21)$ & $193 \pm 120$ & $2,396 \pm 1,424$ & $47 \pm 21$ \\
\hline Curative (C) $(n=36)$ & $364 \pm 198$ & $4,826 \pm 3,613$ & $92.9 \pm 55$ \\
\hline \multirow[t]{3}{*}{ P-value } & O vs. $R: P=0.140$ & O vs. R: $P=0.774$ & O vs. R: $P=0.045^{*}$ \\
\hline & R vs. C: $P=0.002^{*}$ & R vs. C: $P=0.005^{*}$ & R vs. $C: P=0.003^{*}$ \\
\hline & O vs. $C: P=0.323$ & O vs. C: $P=0.043^{*}$ & O vs. C: $P=0.843$ \\
\hline
\end{tabular}

DAP, dose-area product; AK, air-kerma; FT, fluoroscopic time; AVM, arteriovenous malformation.

${ }^{*}$ Remained significant. 
Our data showed great variability of dose levels between categories, up to a 3.8-fold difference in median values between diagnostic cerebral angiography and AVM embolization, mainly due to the difference in procedure complexity and operator and institutional experience.

Table 8 shows a comparison between our results and those published in the literature. ${ }^{8-14}$ For cerebral angiography, when comparing radiation dose with that in the available literature, DAP, AK, and FT were found to be comparable. While comparing the radiation dose with our previous data, ${ }^{8}$ third-quartile DAP and AK values were found to be significantly lower than the published reference (Table 8). A significant dose reduction in 5 out of 22 hospitals was attributed to the introduction of an advanced technology system. The dose reduction in the other 8 centers was achieved by privileging a low-dose technique (low dose fluoroscopy and reducing the number images in DSA).

For aneurysmal embolization, when comparing radiation dose with that in the available literature, DAP, AK, and FT were found to be comparable. However, when comparing radiation dose with our previous data, third-quartile DAP and AK values were found to be significantly lower than the published references (Table 8). While fluoroscopy time was comparable to other studies, the number of angiographic images was much higher.

In the present study, DAP of aneurysm treatment was not significantly different in terms of endovascular technique and aneurysmal location, but was associated with sex and procedural complications. Application of a stent or balloon-assisted technique in more complex aneurysms yielded a higher AK (mean 2,994 mGy) and FT (mean 51 minutes) when compared with a simple catheter technique using 1 or 2 microcatheters $(P<0.05)$. When we assessed the procedural factor contributing to increased radiation dose during aneurysmal coiling, the occurrence of complications resulted in increased patient dose, as additional imaging was required to treat the complications. However, the location of an aneurysm was not a significant factor for increased radiation dose. Acton et al. ${ }^{15}$ argued that aneurysm location is the biggest determinant of radiation dose during coiling procedures; therefore, they suggested separate RLs between anterior and posterior circulation coiling procedures. As wide variation in the RLS for intracranial aneurysmal embolization was evident, the results of this study highlight the need to monitor doses for aneurysm coiling procedures in each country.

For stroke intervention, to our knowledge, this study provides the first radiation data related to mechanical thrombolysis in Korea. When comparing radiation dose with recent other studies, all radiologic dose parameters for our data were found to be higher than in other studies. ${ }^{13,14}$

In the present study, DAP was not significantly different in terms of occlusion site, result of successful recanalization, but higher radiation dose was associated with sex, number of device passages, and occlusion removal technique. Male patients received higher doses than female patients, although sex was not suspected to be a factor influencing the radiation dose in stroke interventions. However, we did not consider the patient's morphology, as this might be a confounding factor, considering that men are generally heavier than women. As we usually use an automatic exposure control system for the fluoroscopic machine in most of our procedures, different habitus can affect the dose production setting to maintain image brightness controlled by automatic exposure algorithms. While the number of attempts required to remove a thrombus is known to reflect the complexity of the procedure, this parameter proved to be the most sig-

Table 8. Comparison of 3rd quartile values from this study with other international studies

\begin{tabular}{|c|c|c|c|c|c|c|c|c|}
\hline & \multicolumn{4}{|c|}{ This study } & \multicolumn{4}{|c|}{ Other studies } \\
\hline & $\begin{array}{c}\text { DAP } \\
\left(\mathrm{Gy} \cdot \mathrm{cm}^{2}\right)\end{array}$ & $\begin{array}{c}\text { AK } \\
\text { (mGy) }\end{array}$ & $\begin{array}{c}\mathrm{FT} \\
(\mathrm{min})\end{array}$ & $\mathrm{NI}$ & $\begin{array}{c}\text { DAP } \\
\left(\mathrm{Gy} \cdot \mathrm{cm}^{2}\right)\end{array}$ & $\begin{array}{c}\text { AK } \\
(m G y)\end{array}$ & $\begin{array}{l}\mathrm{FT} \\
(\min )\end{array}$ & $\mathrm{NI}$ \\
\hline Cerebral angiography & 101 & 711 & 13 & 637 & $90^{8}, 107^{9}, 144^{8}$ & $630^{10}, 921^{8}$ & $11^{10}, 12^{8,9}$ & $\begin{array}{c}287^{8}, 390^{10} \\
550^{9}\end{array}$ \\
\hline Aneurysm embolization & 200 & 3,458 & 57 & 1,000 & $\begin{array}{c}189^{10}, 271^{8} \\
349^{11}\end{array}$ & $\begin{array}{c}2,770^{10}, 4,471^{8} \\
4,750^{12}\end{array}$ & $58^{10}, 65^{8}, 90^{12}$ & $\begin{array}{c}567^{8}, 1,080^{10} \\
1,350^{12}\end{array}$ \\
\hline Stroke thrombolysis & 225 & 1,590 & 45 & 800 & $148^{13}, 162^{14}$ & $730^{13}, 854^{14}$ & $42^{14}$ & $559^{14}$ \\
\hline AVM embolization & 412 & 4,447 & 99 & 1,621 & $\begin{array}{c}285^{10}, 435^{11} \\
550^{12}\end{array}$ & $3,230^{10}, 6,000^{12}$ & $\begin{array}{c}61^{11}, 68^{10} \\
135^{12}\end{array}$ & $970^{10}, 1,410^{11}$ \\
\hline
\end{tabular}

DAP, dose-area product; AK, air-kerma; FT, fluoroscopic time; NI, number of image frames; AVM, arteriovenous malformation. 
nificant factor for affecting patient dose. Although radiation dose for a combined technique was higher than for a single device technique, no significant difference in dose between aspiration and stent retriever techniques was found. These results suggest either aspiration or stent retriever can be used if there is no difference regarding clinical outcome for dosimetric considerations.

The establishment of useful local RLs also requires the inclusion of sufficient data, which can be a challenge for individual neurointerventional units. This was observed in the setting of AVM treatment in the present study. The number of AVM procedures performed was relatively small, and the 75th percentile DAP value was $412 \mathrm{~Gy} \cdot \mathrm{cm}^{2}$. When comparing radiation dose with the available literature, a large variability was evident. ${ }^{12}$ Our results were generally comparable to other reported data.

Setting up DRLs for dose-intensive examinations involving fluoroscopy is a difficult task due to the large variability in FT and the number of images, leading to a wide distribution of patient doses. Furthermore, unique institutional patterns and operator preferences for INR procedures can cause difficulty in making radiation dose comparisons between hospitals. ${ }^{16}$ Nevertheless, this study indicates our values of various radiation doses of INR procedures were within the range of previous published reports and concordance of the data with those reports. Therefore, our proposed RLs would be valuable in comparing and monitoring radiation doses.

INR procedures show wide variety and complexity, and are continuously progressing, so radiation dose may be higher with complex, newer, or meticulous procedures. ${ }^{17}$ Nevertheless, it is each practitioner's responsibility to investigate his or her own practice and to limit unnecessary radiation exposure according to the ALARA (As Low as Reasonably Achievable) principle. ${ }^{18-21}$

This study has limitations. First, we collected retrospective registry data even though we designed a prospective study without controlling for potential sources of bias. Second, our data did not include information on the patient's body mass index or factors that determine the complexity of various procedures. However, previous studies have shown that the amount of radiation for INR procedures is much more affected by procedure complexity than by patient size and weight. Miller et al. ${ }^{12}$ considered that it is sufficient to use reference levels that have not been corrected for patient body habitus. Third, we did not evaluate the complexity of the various neurointerventional procedures. Further investigation with larger populations and prospective evaluation is clearly warranted in order to validate our results.

\section{CONCLUSION}

In this study, patient radiation exposure was collected and analyzed for various neurointerventional procedures of varying complexities and found to be comparable to the published literature. Various dose reference levels introduced in this study promote the optimization of patient doses in diagnostic and therapeutic INR procedures. Proposed third quartile DAP $\left(\mathrm{Gy} \cdot \mathrm{cm}^{2}\right)$ values were 101.6 for diagnostic cerebral angiography, 199.9 for aneurysm coiling, 225.1 for stroke thrombolysis, and 412.3 for AVM embolization. Continual evolution of practices and technologies requires regular updates of reference levels.

\section{Acknowledgments}

The authors are very grateful to the staff of the 22 hospitals (nurses, technical personnel, and radiologists) who took the time to collect and check the data.

\section{Fund}

This study was supported by the Korean Society of Interventional Neuroradiology (KSIN) research grant 2020.

\section{Ethics Statement}

This study waived approval of the institutional review board. Informed consent for publication is not required.

\section{Conflicts of Interest}

BK has been the Associate Editor of the Neurointervention since 2020. No potential conflict of interest relevant to this article was reported.

DJK has been the Associate Editor of the Neurointervention since 2018. No potential conflict of interest relevant to this article was reported.

YS has been the Assistant Editor of the Neurointervention since 2019. No potential conflict of interest relevant to this article was reported.

No other authors have any conflict of interest to disclose.

\section{Author Contribution}

Concept and design: YKI, BK, HWJ, SHS, YDW, YL, DJK, PJ, CR, SS, DSC, SSC, SHK, JSB, JR, YS, WSJ, NH, SHB, JJP, SML, JK, and 
WY. Analysis and interpretation: YKI, BK, HWJ, SHS, YDW, YL, DJK, PJ, CR, SS, DSC, SSC, SHK, JSB, JR, YS, WSJ , NH, SHB, JJP, SML, JK, and WY. Data collection: YKI, BK, HWJ, SHS, YDW, YL, DJK, PJ, CR, SS, DSC, SSC, SHK, JSB, JR, YS, WSJ , NH, SHB, $J J P, S M L, J K$, and WY. Writing the article: YKI and BK. Critical revision of the article: YKI and BK. Final approval of the article: YKI. Statistical analysis: BK. Obtained funding: YKI. Overall responsibility: YKI.

\section{ORCID}

Yon-Kwon Ihn: https://orcid.org/0000-0002-3770-308X Bum-soo Kim: https://orcid.org/0000-0002-3870-6813 Hae Woong Jeong: https://orcid.org/0000-0002-4912-9302 Sang Hyun Suh: https://orcid.org/0000-0002-7098-4901 Yoo Dong Won: https://orcid.org/0000-0002-4422-591X Young-Jun Lee: https://orcid.org/0000-0002-9971-9394 Dong Joon Kim: https://orcid.org/0000-0002-7035-087X Pyong Jeon: https://orcid.org/0000-0002-8642-1791 Chang-Woo Ryu: https://orcid.org/0000-0002-4674-7295 Sang-il Suh: https://orcid.org/0000-0001-8933-0492 Dae Seob Choi: https://orcid.org/0000-0001-8103-3303 See Sung Choi: https://orcid.org/0000-0002-4442-9410 Sang Heum Kim: https://orcid.org/0000-0001-7504-5148 Jun Soo Byun: https://orcid.org/0000-0003-3210-9505 Jieun Rho: https://orcid.org/0000-0002-6876-3990 Yunsun Song: https://orcid.org/0000-0003-4738-0533 Woo Sang Jeong: https://orcid.org/0000-0002-0727-3744 Noah Hong: https://orcid.org/0000-0003-2938-3474 Sung Hyun Baik: https://orcid.org/0000-0003-3738-8988 Jeong Jin Park: https://orcid.org/0000-0001-9325-164X Soo Mee Lim: https://orcid.org/0000-0003-0782-8583 Jung-Jae Kim: https://orcid.org/0000-0002-4669-8577 Woong Yoon: https://orcid.org/0000-0002-8598-3127

\section{REFERENCES}

1. Alexander MD, Oliff MC, Olorunsola OG, Brus-Ramer M, Nickoloff EL, Meyers PM. Patient radiation exposure during diagnostic and therapeutic interventional neuroradiology procedures. J Neurointerv Surg 2010;2:6-10

2. Valentin J. Avoidance of radiation injuries from medical interventional procedures. Ann ICRP 2000;30:7-67

3. The 2007 recommendations of the International Commission on Radiological Protection. ICRP publication 103. Ann ICRP 2007;37:1-332
4. Vañó E, Miller DL, Martin CJ, Rehani MM, Kang K, Rosenstein M, et al.; Authors on behalf of ICRP. ICRP publication 135: diagnostic reference levels in medical imaging. Ann ICRP 2017:46:1-144

5. Aroua A, Rickli H, Stauffer JC, Schnyder P, Trueb PR, Valley JF, et al. How to set up and apply reference levels in fluoroscopy at a national level. Eur Radiol 2007;17:1621-1633

6. Chung JW. Evaluation of patient dose in interventional radiology. Seoul: Korea Food \& Drug Administration; 2007

7. Chun CW, Kim BS, Lee CH, Ihn YK, Shin YS. Patient radiation dose in diagnostic and interventional procedures for intracranial aneurysms: experience at a single center. Korean J Radiol 2014;15:844-849

8. Ihn YK, Kim BS, Byun JS, Suh SH, Won YD, Lee DH, et al. Patient radiation exposure during diagnostic and therapeutic procedures for intracranial aneurysms: a multicenter study. Neurointervention 2016;11:78-85

9. Vano $E$, Järvinen $H$, Kosunen A, Bly R, Malone J, Dowling A, et al. Patient dose in interventional radiology: a European survey. Radiat Prot Dosimetry 2008;129:39-45

10. Etard C, Bigand E, Salvat C, Vidal V, Beregi JP, Hornbeck A, et al. Patient dose in interventional radiology: a multicentre study of the most frequent procedures in France. Eur Radiol 2017;27:4281-4290

11. Kien N, Rehel JL, Etard C, Aubert B. [Patient dose during interventional neuroradiology procedures: results from a multi-center study]. J Radiol 2011;92:1101-1112 French

12. Miller DL, Kwon D, Bonavia GH. Reference levels for patient radiation doses in interventional radiology: proposed initial values for U.S. practice. Radiology 2009;253:753-764

13. Guenego A, Mosimann PJ, Pereira VM, Nicholson P, Zuber K, Lotterie JA, et al.; RADON Investigators. Proposed achievable levels of dose and impact of dose-reduction systems for thrombectomy in acute ischemic stroke: an international, multicentric, retrospective study in 1096 patients. Eur Radiol 2019;29:35063515

14. Farah J, Rouchaud A, Henry T, Regen C, Mihalea C, Moret J, et al. Dose reference levels and clinical determinants in stroke neuroradiology interventions. Eur Radio/ 2019;29:645-653

15. Acton H, James K, Kavanagh RG, O'Tuathaigh C, Moloney $D$, Wyse $G$, et al. Monitoring neurointerventional radiation doses using dose-tracking software: implications for the establishment of local diagnostic reference levels. Eur Radiol 2018;28:3669-3675

16. Weyland CS, Hemmerich F, Möhlenbruch MA, Bendszus M, Pfaff JAR. Radiation exposure and fluoroscopy time in mechanical thrombectomy of anterior circulation ischemic stroke depend- 
ing on the interventionalist's experience-a retrospective single center experience. Eur Radiol 2020;30:1564-1570

17. Forbrig R, Ozpeynirci Y, Grasser M, Dorn F, Liebig T, Trumm CG. Radiation dose and fluoroscopy time of modern endovascular treatment techniques in patients with saccular unruptured intracranial aneurysms. Eur Radio/ 2020;30:4504-4513

18. Peter Y, Speelman A, Daries V. Measurement of the average radiation dose to the local skin and thyroid gland during intracranial aneurysm coil embolization. Radiography (Lond) 2021;27:255-259

19. Kahn EN, Gemmete JJ, Chaudhary N, Thompson BG, Chen K, Christodoulou EG, et al. Radiation dose reduction during neurointerventional procedures by modification of default settings on biplane angiography equipment. J Neurointerv Surg 2016;8:819-823

20. Morris PP, Geer CP, Singh J, Brinjikji W, Carter RE. Radiation dose reduction during neuroendovascular procedures. J Neurointerv Surg 2018;10:481-486

21. Kawauchi S, Chida K, Moritake T, Hamada Y, Matsumaru Y, Tsuruta W, et al. Treatment of internal carotid aneurysms using pipeline embolization devices: measuring the radiation dose of the patient and determining the factors affecting it. Radiat Prot Dosimetry 2020;188:389-396 